\title{
Correction to: Facilitating the implementation of clinical technology in healthcare: what role does a national agency play?
}

Gill Harvey ${ }^{1,2^{*}}$, Sue Llewellyn ${ }^{2}$, Gregory Maniatopoulos ${ }^{3}$, Alan Boyd ${ }^{2}$ and Rob Procter ${ }^{4}$

\section{Correction}

Upon publication of the original article [1], Gregory Maniatopoulos' name was incorrectly given as 'Greg Maniatopoulous'. This has now been corrected in the original article.

\begin{abstract}
Author details
${ }^{1}$ Adelaide Nursing School, University of Adelaide, Adelaide, SA 5005, Australia. ${ }^{2}$ Alliance Manchester Business School, University of Manchester, Booth Street East, Manchester M13 9SS, UK. ${ }^{3}$ Institute of Health \& Society, Newcastle University, Richardson Road, Newcastle upon Tyne NE2 4AX, UK. ${ }^{4}$ Department of Computer Science, University of Warwick, Warwick CV4 7AL, UK.
\end{abstract}

Received: 31 May 2018 Accepted: 31 May 2018

Published online: 11 June 2018

\section{Reference}

1. Harvey G, Llewellyn S, Maniatopoulos G, Boyd A, Procter R. Facilitating the implementation of clinical technology in healthcare: what role does a national agency play? BMC Health Serv Res. 2018;18:347.

\footnotetext{
* Correspondence: gillian.harvey@adelaide.edu.au

${ }^{1}$ Adelaide Nursing School, University of Adelaide, Adelaide, SA 5005, Australia ${ }^{2}$ Alliance Manchester Business School, University of Manchester, Booth Street East, Manchester M13 95S, UK

Full list of author information is available at the end of the article
} 